\title{
ИССЛЕДОВАНИЕ ПРИМЕНЕНИЯ ПЕНОПОЛИУРЕТАНА ПРИ ОТРИЦАТЕЛЬНЫХ ТЕМПЕРАТУРАХ МЕТОДОМ НАПЫЛЕНИЯ
}

\section{Торопкин Даниил Олегович} Алексеева Наталья Дмитриевна магистранты

Шадрина Мария Николаевна к.т.н., доцент

ФГБОУ ВО «Новосибирский государственный архитектурно-строительный университет (Сибстрин)»

Аннотация: Выполнены исследования характеристик пенополиуретана (ППУ), выявлены факторы риска нанесения ППУ методом напыления на поверхности при отрицательных температурах, сделаны выводы и представлены возможные пути решения проблемы. Данные исследования проведены в г. Новосибирске, где проблема актуальна из-за особенностей климата.

Ключевые слова: пенополиуретан, напыление, нанесение пенополиуретана при отрицательных температурах.

\section{INVESTIGATION OF THE USE OF POLYURETHANE FOAM AT SUBZERO TEMPERATURES}

\section{Toropkin Daniil Olegovich Alekseeva Natalia Dmitrievna Shadrina Maria Nikolaevna}

\footnotetext{
Abstract: Studies of the characteristics of raw materials were carried out, the risk factors of PU foam at negative temperatures were identified, conclusions were drawn and possible solutions to the problem were presented. These studies were conducted in Novosibirsk, where the problem is relevant due to the peculiarities of the climate.

Key words: polyurethane foam, spraying, application of polyurethane foam at negative temperatures.
} 


\section{Введение}

На строительном рынке представлено множество современных теплоизоляционных материалов с высокой энергоэффективностью. Наряду с каменной ватой и экструзионным пенополистиролом всё большой интерес у застройщиков вызывает такой способ утепления как напыление ППУ.

Проблема применения теплоизоляции из пенополиуретана установками высокого давления при отрицательных температурах встает остро по причине того, что Новосибирская область находится в зоне континентального, умеренно-теплого климата. Здесь температура выше $+5^{0} \mathrm{C}$ поднимается лишь 5 месяцев в году, что сокращает период времени, в который возможна работа с компонентами.

\section{Постановка задачи}

Авторами работы была поставлена задача: исследовать характеристики ППУ, выявить факторы риска при нанесении ППУ методом напыления при отрицательных температурах и сделать соответствующие выводы.

\section{Методика исследования}

Опытным путем были выделены следующие факторы риска при нанесении ППУ при отрицательных температурах: перерасход сырья, ухудшение теплоизоляционных свойств, стекание, усадка, снижение адгезии.

С целью исследования характеристик ППУ был проведен ряд экспериментов по некоторым факторам риска.

Эксперимент № 1. Исследование перерасхода сырья.

Температура окружающей среды, поверхности и самих компонентов существенно влияет на протекание химической реакции, в частности на коэффициент вспенивания ППУ. Выделяющееся в ходе экзотермической реакции получения ППУ тепло затрачивается не на вспенивание, а на нагрев поверхности и компенсацию низкой температуры воздуха. В результате происходит переуплотнение получаемой пены, как следствие перерасход материала и повышение себестоимости работ. Чем ниже температура, тем больше перерасход материала. К примеру, при температурах ниже $-10{ }^{\circ} \mathrm{C}$ перерасход ППУ компонентов может быть более $50 \%$ от запланированного.

В рамках эксперимента было проведено сравнение утепления двух одинаковых металлических ангаров: первый ангар утеплялся пенополиуретаном при температуре воздуха снаружи $+18^{\circ} \mathrm{C}$, второй - при температуре $-3^{\circ} \mathrm{C}$. Оборудование для напыления находилось в закрытом кузове машины, где на протяжении всего процесса работы поддерживалась температура 
$+15{ }^{\circ} \mathrm{C}$. Температура компонентов в установке также стабильно поддерживалась изоционат $+65^{\circ} \mathrm{C}$, полиол $+60^{\circ} \mathrm{C}$. Шланги для подачи смеси имели температуру $+60^{\circ} \mathrm{C}$.

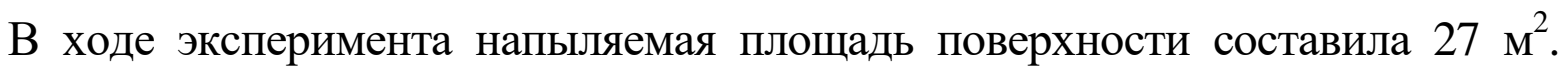
Перерасход сырья составил $4 \mathrm{~m}^{2}$, что составляет $15 \%$.

Эксперимент №2. Определение силы адгезии ППУ к поверхностям.

При напылении ниже $10^{\circ} \mathrm{C}$ появляется риск образования конденсата при контакте теплой реакционной массы с холодной подложкой. Это может привести к частичному или полному отслоению ППУ от напыляемой поверхности.

Для проведения этого эксперимента было изготовлено 9 образцов, 6 из которых застывали при отрицательной температуре и 3 при нормальных условиях. Материалом для экспериментов послужили дерево, металл и кирпич. Проверка адгезии проводилась прибором адгезометр ПСО-МГ 4.

Результаты эксперимента представлены в таблице 1.

Таблица 1

Результаты эксперимента

\begin{tabular}{|c|c|c|c|c|c|c|}
\hline \multirow{2}{*}{$\begin{array}{c}\text { Материал } \\
\text { поверхности }\end{array}$} & \multicolumn{2}{|c|}{$\mathrm{t}=+16^{\circ} \mathrm{C}$} & \multicolumn{2}{|c|}{$\mathrm{t}=-\mathbf{8}^{\circ} \mathrm{C}$} & \multicolumn{2}{|c|}{$\mathrm{t}=-16^{\circ} \mathrm{C}$} \\
\hline & \multicolumn{6}{|c|}{ Сила адгезии } \\
\hline Кирпич & 0,30 кН & $0,12 \mathrm{MПа}$ & 0,29 кН & $0,12 \mathrm{MПа}$ & $0,29 \kappa \mathrm{H}$ & $0,12 \mathrm{MПа}$ \\
\hline Дерево & $0,30 \kappa \mathrm{H}$ & $0,12 \mathrm{MПа}$ & 0,29 кН & $0,12 \mathrm{MПа}$ & 0,29 кН & $0,12 \mathrm{MПа}$ \\
\hline Металл & $0,40 \kappa \mathrm{H}$ & $0,16 \mathrm{MПа}$ & $0,38 \kappa \mathrm{H}$ & $0,16 \mathrm{MПа}$ & $0,38 \mathrm{\kappa H}$ & $0,16 \mathrm{MПа}$ \\
\hline
\end{tabular}

Эксперимент №3. Исследование усадки и стекания пенополиуретана.

Усадка - это процесс изменение объемных и линейных размеров материала в сторону уменьшения при определенных условиях. В процессе отверждения ППУ происходит стандартная усадка в пределах 5-7\%.

Одна из причин усадки - несоблюдение параметров вспенивания.

Причины несоответствия:

- компоненты не прогреты до значений указанных в ТУ,

- холодная поверхность для нанесения ППУ расходует энергию реакции не на вспенивание, а на разогрев,

- температура окружающей среды ниже регламентируемой и создается разность температур на границе раздела фаз воздух/ППУ.

Усадка ППУ происходит по всему объему системы, если выполняется следующее неравенство: 
$\mathrm{P}>2 \mathrm{ba} / \mathrm{c}$,

где P - внутриячеистое давление вспенивающего газа, b - толщина окружающей ячейку пленки, a - напряжение при которой наступает разрушающее растяжении пленки, с - толщина единичной ячейки.

При несоблюдении технических условий усадка составляет $20 \%-50 \%$.

Объект исследования - неотапливаемое здание с кирпичными стенами. При проведении эксперимента была зафиксирована температура воздуха $\mathrm{t}=-8^{\circ} \mathrm{C}$. Толщина напыления составила 7 мм. В течение ночи наблюдался снегопад. На следующий день толщина ППУ составила 6,6 мм, что свидетельствует об усадке пенополиуретана.

Итак, усадка составила 6\%, что находится в пределах нормы.

Эксперимент также показал, что из-за низкой температуры, схватывание было медленнее, чем при положительных температурах, вследствие чего происходило стекание материала. «Сосулек» не образовывалось.

В результате был сделан вывод: с понижением температуры резко снижается вспенивающая способность ППУ компонентов, скорость реакции замедляется, и пена начинает стекать по стене. В случае напыления на потолочную поверхность это будет выглядеть как «сосульки» из ППУ.

\section{Выводы}

В отличие от работы при благоприятных температурных условиях, работа при отрицательных температурах может быть затруднена рядом факторов: компоненты смеси должны быть прогреты до рабочих температур, есть риск возникновения трещин, стекание, усадка ППУ и перерасход сырья. Все эти факторы можно устранить, повысив температуру поверхности напыления, создав нормальные условия.

Возможные решения для сокращения теплопотерь при отрицательных температурах:

1. Выбор зимней системы компонентов.

2. Подогрев ППУ компонентов различными способами. Зимние системы компонентов также требуют подогрева при отрицательных температурах. Способы подогрева: обогревающие маты, рециркуляция при помощи установки с режимом прогрева; использование нагревательных элементов, прогрев теплым воздухом из тепловых пушек, исключение контакта компонентов смеси с холодными поверхностями.

3. Прогрев напыляемой поверхности. Температура напыляемой поверхности должна быть не ниже $+10^{\circ} \mathrm{C}$, но не выше $+45^{\circ} \mathrm{C}$. 
4. Обогрев шлангов и воздуха. Оснащение установки для напыления ППУ обогреваемыми шлангами и системой подачи теплого воздуха в пистолет-распылитель.

5. Сооружение «тепляков» для оборудования и компонентов.

\section{Список литературы}

1. ГОСТ 59561-2021 Изделия теплоизоляционные из пенополиуретана (ППУ) и пенополиизоцианурата (ПИР) для строительства, напыляемые на месте производства работ. Жесткие пенополиуретановые и пенополиизоциануратные системы перед применением. Технические условия.

2. В.А. Голубев, Справочное пособие действующей нормативной документации на жесткие пенополиуретаны получаемые методом напыления и заливки, применяемых в качестве теплоизоляции ограждающих конструкций в строительстве, в агропромышленном комплексе и других отраслях народного хозяйства, Москва 2019.

3. «Основы и рекомендации по методу напыления ПУ-системы» от производителя АО "Хантсман-НМГ". 